\title{
Lipoprotein Lipase Is Synthesized by Macrophage- derived Foam Cells in Human Coronary Atherosclerotic Plaques
}

\author{
Kevin D. O'Brien,"* David Gordon,"Samir Deeb," Marina Ferguson," and Alan Chait" \\ ${ }^{*}$ Divisions of Cardiology; ${ }^{\ddagger}$ Metabolism, Endocrinology, and Nutrition; and "Medical Genetics, Department of Medicine, \\ and ${ }^{8}$ Department of Pathology, University of Washington, Seattle, Washington 98195
}

\begin{abstract}
Lipoprotein lipase (LPL), hydrolyzes the core triglycerides of lipoproteins, thereby playing a role in their maturation. LPL may be important in the metabolic pathways that lead to atherosclerosis, since it is secreted in vitro by both of the predominant cell types of the atherosclerotic plaque, i.e., macrophages and smooth muscle cells. Because of uncertainty concerning the primary cellular source of LPL in atherosclerotic lesions, in situ hybridization assays for LPL mRNA were performed on 12 coronary arteries obtained from six cardiac allograft recipients. Macrophages and smooth muscle cells were identified on adjacent sections with cell-specific antibodies and foam cells were identified morphologically. LPL protein was localized using a polyclonal antibody.

LPL mRNA was produced by a proportion of plaque macrophages, particularly macrophage-derived foam cells, but was not detected in association with any intimal or medial smooth muscle cells. These findings were confirmed by combined immunocytochemistry and in situ hybridization on the same tissue sections. LPL protein was detected in association with macrophage-derived foam cells, endothelial cells, adventitial adipocytes, and medial smooth muscle cells, and, to a lesser extent, in intimal smooth muscle cells and media underlying well-developed plaque. These results indicate that macrophage-derived foam cells are the primary source of LPL in atherosclerotic plaques and are consistent with a role for LPL in the pathogenesis of atherosclerosis. (J. Clin. Invest. 1992. 89:1544-1550.) Key words: in situ hybridization • immunocytochemistry • modified lipoproteins • cytokines $\bullet$ atherogenesis
\end{abstract}

\section{Introduction}

Lipoprotein lipase (LPL) ${ }^{1}$ is an enzyme that hydrolyzes the core triglycerides of chylomicrons and very low density lipoproteins, thereby playing a role in their metabolism. It also hydrolyzes triglycerides in the core of low density lipoprotein, thereby remodeling this lipoprotein class as well (1). Zilversmit

This work was presented in part at the Annual Meeting of The American Society for Clinical Investigation, Seattle, WA, on 6 May 1991.

Address correspondence to Alan Chait, M.D., Division of Metabolism, Endocrinology, and Nutrition, RG-26, University of Washington, Seattle, WA 98195.

Received for publication 2 October 1991 and in revised form 16 December 1991

1. Abbreviation used in this paper: LPL, lipoprotein lipase.

J. Clin. Invest.

(C) The American Society for Clinical Investigation, Inc.

0021-9738/92/05/1544/07 \$2.00

Volume 89, May 1992, 1544-1550
(2) first proposed that LPL may be important in atherosclerosis by hypothesizing that hydrolysis of the triglyceride-rich lipoproteins by LPL at the endothelial lining of arteries could lead to the formation of atherogenic remnants, which might be taken up by arterial wall cells and lead to cholesterol deposition. He subsequently demonstrated the presence of LPL activity in the intima of bovine aorta (3).

LPL was shown to be produced by murine peritoneal (4), human monocyte-derived $(5,6)$, and rabbit alveolar $(6)$ macrophages, and by pig aortic smooth muscle cells (7). However, LPL production by cultured human arterial smooth muscle cells has never been reported. In vitro experiments have also demonstrated that LPL might promote lipid accumulation by cells $(8,9)$. LPL can metabolize VLDL and chylomicrons to remnants which have an increased rate of uptake by macrophages (8). LPL also can modify LDL to a form with an increased rate of uptake by both macrophages and smooth muscle cells (9). Thus, in vitro studies have demonstrated that LPL may be produced by both of the predominant cell types of the plaque, i.e., macrophages and smooth muscle cells, and may modify certain lipoproteins to forms that are taken up more readily by cells.

In addition to the observations of Zilversmit, other in vivo experiments have demonstrated the presence of LPL in arterial tissue. Camps et al. demonstrated that medial smooth muscle cells of normal guinea pig aorta produce LPL mRNA, as detected by in situ hybridization, and are associated with LPL protein, as determined by immunocytochemistry using a polyclonal antibody directed against guinea pig LPL (10). Jonasson et al. used a polyclonal anti-LPL antibody directed against bovine milk LPL on human carotid arteries obtained at endarterectomy, and demonstrated that LPL protein was associated with HLA-DR negative smooth muscle cells, but not with HLA-DR positive smooth muscle cells. Furthermore, LPL protein was not detected in association with macrophages, or with foam cells (11). Therefore, a conflict exists between in vitro studies, in which LPL production has been most reproducibly associated with macrophages, and in vivo experiments, in which LPL protein has been found to be associated with normal medial smooth muscle cells in guinea pigs, or with "nonactivated" (i.e., HLA-DR negative) smooth muscle cells in human carotid plaques. Therefore, the present study was undertaken to determine which of the cell types in human coronary atherosclerotic plaques produce LPL, as determined by in situ hybridization, and with which cell types LPL protein is associated. The results indicate that macrophage foam cells are the major source of LPL in atherosclerotic plaques, consistent with in vitro observations.

\section{Methods}

Arterial tissue. 12 coronary artery segments were obtained from hearts removed from six patients undergoing orthotopic cardiac transplanta- 
tion. These segments were fixed in either fresh $4 \%$ paraformaldehyde or $10 \%$ formalin and paraffin-embedded. The etiology of cardiomyopathy was idiopathic in three patients, ischemic in two, and valvular in one.

Immunocytochemistry. Single-label immunoperoxidase staining of tissues was performed as described previously (12), using the cell-specific monoclonal antibodies HAM-56, which recognizes human macrophages (13), and HHF-35, which recognizes muscle cell actin, and therefore is specific for smooth muscle cells when used in this context (12). HHF-35 and HAM-56 were kindly provided by Dr. Allen Gown, University of Washington. HAM-56 was used at a titer of 1:4,000 and HHF-35 at a titer of 1:10,000. Briefly, tissue sections were deparaffinized with xylene, rehydrated with graded alcohols, and washed with phosphate-buffered saline. The slides were incubated $(30 \mathrm{~min})$ with the primary antibody, washed with PBS, after which a biotin-labeled secondary antibody was applied ( $30 \mathrm{~min})$, followed by an avidin-biotinylated-peroxidase conjugate $(30 \mathrm{~min})$. Standard peroxidase substrate, 3,3'-diaminobenzidine (Sigma Chemical Co., St. Louis, MO) was then added, yielding a brown reaction product, and the slide was counterstained with hematoxylin or methyl green.

Characterization of anti-LPL antibody LPL-5780. Rabbit antiserum containing LPL-5780, a polyclonal antibody directed against bovine LPL, and a kind gift of Dr. John Brunzell, University of Washington, was used in a dilution of 1:500 to detect LPL on arterial tissues. Specificity of this antibody for LPL was determined by the following criteria: ( $a$ ) inhibition of triglyceride hydrolysis by $85 \%$ when preincubated at a dilution of 1:16 with LPL in an LPL activity assay; $(b)$ recognition on Western blots of macrophage-conditioned media of a single band with the same molecular weight as a bovine LPL standard; $(c)$ staining of 4\% paraformaldehyde-fixed THP-1 cells that had been exposed to phorbol ester for $24 \mathrm{~h}$, conditions that lead to the stimulation of LPL secretion $(14,15)$ while uninduced THP-1 cells did not stain with the antibody; and $(d)$ difference in staining pattern from that found with normal rabbit serum used at the same titer.

Riboprobe preparation. A 1.4-kb human LPL cDNA fragment (16), corresponding to base pairs 271-1630 in the expression vector pGEM 1 was transcribed into an antisense riboprobe using reagents obtained from Promega Biotec (Madison, WI), except ${ }^{35}$ S-UTP, which was obtained from New England Nuclear (Boston, MA). A sense riboprobe also was synthesized from a $1-\mathrm{kb}$ fragment of the LPL coding sequence. The transcription reaction mixture contained $1 \mu \mathrm{g}$ of LPL cDNA (either sense or antisense), $250 \mu \mathrm{Ci}^{35} \mathrm{~S}-\mathrm{UTP}(1,100-1,300 \mathrm{Ci} / \mathrm{mmol}), 500$ $\mu \mathrm{M}$ each of ATP, CTP, and GTP, $40 \mathrm{U}$ RNasin, $10 \mathrm{mM}$ dithiothreitol, $40 \mathrm{mM}$ Tris, and $10 \mathrm{U}$ of either T7 or SP6 polymerase. After $60-75$ min at $37^{\circ} \mathrm{C}$, the cDNA was digested by adding $1 \mathrm{U}$ DNase (Promega) and incubation at $37^{\circ} \mathrm{C}$ for an additional $15 \mathrm{~min}$. Free nucleotides were then separated using a Sephadex G-50 column. Specific activity of the probes ranged from 5 to $30 \times 10^{7} \mathrm{cpm} / \mathrm{mg}$. Probes were stored at $-70^{\circ} \mathrm{C}$ and used within $24 \mathrm{~h}$ of synthesis.

In situ hybridization. Arterial tissue which had been fixed in $4 \%$ paraformaldehyde or $10 \%$ formalin and embedded in paraffin was deparaffinized following standard protocol. The sections were washed with $0.5 \times$ standard saline citrate $(\mathrm{SSC})(1 \times \mathrm{SSC}=150 \mathrm{mM} \mathrm{NaCl}, 15$ $\mathrm{mM} \mathrm{Na}$ citrate, $\mathrm{pH} 7.0)$, digested with proteinase $\mathrm{K}(1 \mu \mathrm{g} / \mathrm{mL})$ (Sigma) in RNase A (Promega) buffer, and then postfixed for $10 \mathrm{~min}$ in paraformaldehyde. Several $0.5 \times$ SSC washes were followed by prehybridization for $2 \mathrm{~h}$ in $50 \mu \mathrm{l}$ of prehybridization buffer $(0.3 \mathrm{M} \mathrm{NaCl}, 20 \mathrm{mM}$ Tris pH 8.0, 5 mM EDTA, $1 \times$ Denhardt's solution, $10 \%$ dextran sulfate, $10 \mathrm{mM}$ DTT). The hybridizations were started by adding 500,000 cpm of ${ }^{35} \mathrm{~S}$-labeled riboprobe in $50 \mu \mathrm{l}$ of prehybridization buffer and allowed to proceed overnight at $50^{\circ} \mathrm{C}$. After hybridization, sections were washed with $0.5 \times \mathrm{SSC}$, treated with RNase A $(20 \mu \mathrm{g} / \mathrm{ml}, 30 \mathrm{~min}$ room temperature), washed in $2 \times \operatorname{SSC}(2 \times 2 \mathrm{~min})$, followed by three high stringency washes in $0.1 \times \mathrm{SSC} / \mathrm{T}$ ween 20 (Sigma) at $37^{\circ} \mathrm{C}$, followed by several $2 \times$ SSC washes. After the tissue was air dried, it was dipped in NTB2 nuclear emulsion (Kodak) and exposed in the dark at $4^{\circ} \mathrm{C}$ for $4 \mathrm{wk}$. After developing, the sections were counterstained with either hematoxylin and eosin or methyl green, dehydrated, and mounted.
Analysis of immunocytochemistry and in situ hybridization of adjacent arterial sections. $6-\mu \mathrm{m}$ serial sections from each of 12 coronary arterial segments stained with hematoxylin and eosin, the cell-specific antibodies HHF-35 and HAM-56, and the antisense riboprobe for LPL mRNA were analyzed in the following manner. Each arterial segment was divided into four quadrants, and the intima of each quadrant scored for the presence or absence of foam cells (as detected by light microscopy), macrophages or smooth muscle cells (as detected immunocytochemically), and LPL mRNA (as detected by in situ hybridization).

Combined immunocytochemistry and in situ hybridization. Immunocytochemistry with either HAM-56 or HHF-35 was performed as described above, with the following exceptions: (a) RNasin (Promega) was added to the primary and secondary antibodies and to the avidinbiotin complex at a concentration of $180 \mathrm{U} / \mathrm{ml} ;(b)$ antibodies were used at two- to fourfold higher concentrations due to the RNasin treatment; and (c) PBS was treated with diethyl pyrocarbonate (Sigma). In situ hybridization then followed immediately and by standard protocol.

\section{Results}

Immunocytochemistry and in situ hybridization of adjacent arterial sections. A low power photomicrograph of a hematoxylin and eosin-stained section from one of the arteries included in the study is shown in Fig. $1 a$. Higher power photomicrographs of the foam cell-rich region in the lower right-hand portion of the artery from adjacent sections of the same artery stained with the cell-specific antibodies show that black grains representing hybridized antisense LPL riboprobe (Fig. $1 b$ ) co-localize with the macrophage marker (HAM-56, Fig. $1 c$ ), but not with the marker for smooth muscle cells (HHF-35, Fig. $1 d$ ), which are located primarily in the fibrous cap (upper left, Fig. 1 $d$ ) and base (lower right, Fig. $1 d$ ) of the plaque. These smooth muscle cells do not synthesize detectable levels of LPL mRNA. In contrast, macrophages, as identified by the antibody HAM56 , are located primarily in the center of this portion of the plaque intima (Fig. $1 \mathrm{c}$ ). Using a sense LPL riboprobe, no specific hybridization is detected (data not shown).

Immunocytochemistry with anti-LPL antibody LPL-5780. LPL protein, as detected immunocytochemically by antibody LPL-5780 staining, was present in association with macrophage-derived foam cells, endothelial cells, adventitial adipocytes, and arterial media underlying sections of intima which were uninvolved with plaque, or which had only diffuse intimal thickening (Fig. $2 a$ ). The staining was particularly strong in foam cell-rich regions (Fig. $2 b$ ). Specific staining with the antibody was also present, though markedly diminished, in intimal smooth muscle cells and in arterial media underlying areas of well-developed plaque (Fig. $2 c$ ).

Distribution of LPL MRNA and cell types in 12 coronary arterial segments. The intima of 48 quadrants from 12 coronary arterial segments were examined for the presence or absence of foam cells, macrophages, smooth muscle cells, and LPL mRNA. Of the 48 quadrants, foam cells were present in $10(21 \%)$, macrophages were identified in $29(60 \%)$, smooth muscle cells were present in $46(96 \%)$, and LPL mRNA was detected by in situ hybridization in $11(23 \%)$. A contingency table was then constructed to evaluate potential associations between the presence or absence of LPL mRNA in a quadrant and the presence or absence of foam cells, macrophages, and smooth muscle cells (Table I). The strongest association observed was between LPL mRNA and foam cells. All foam cell- 

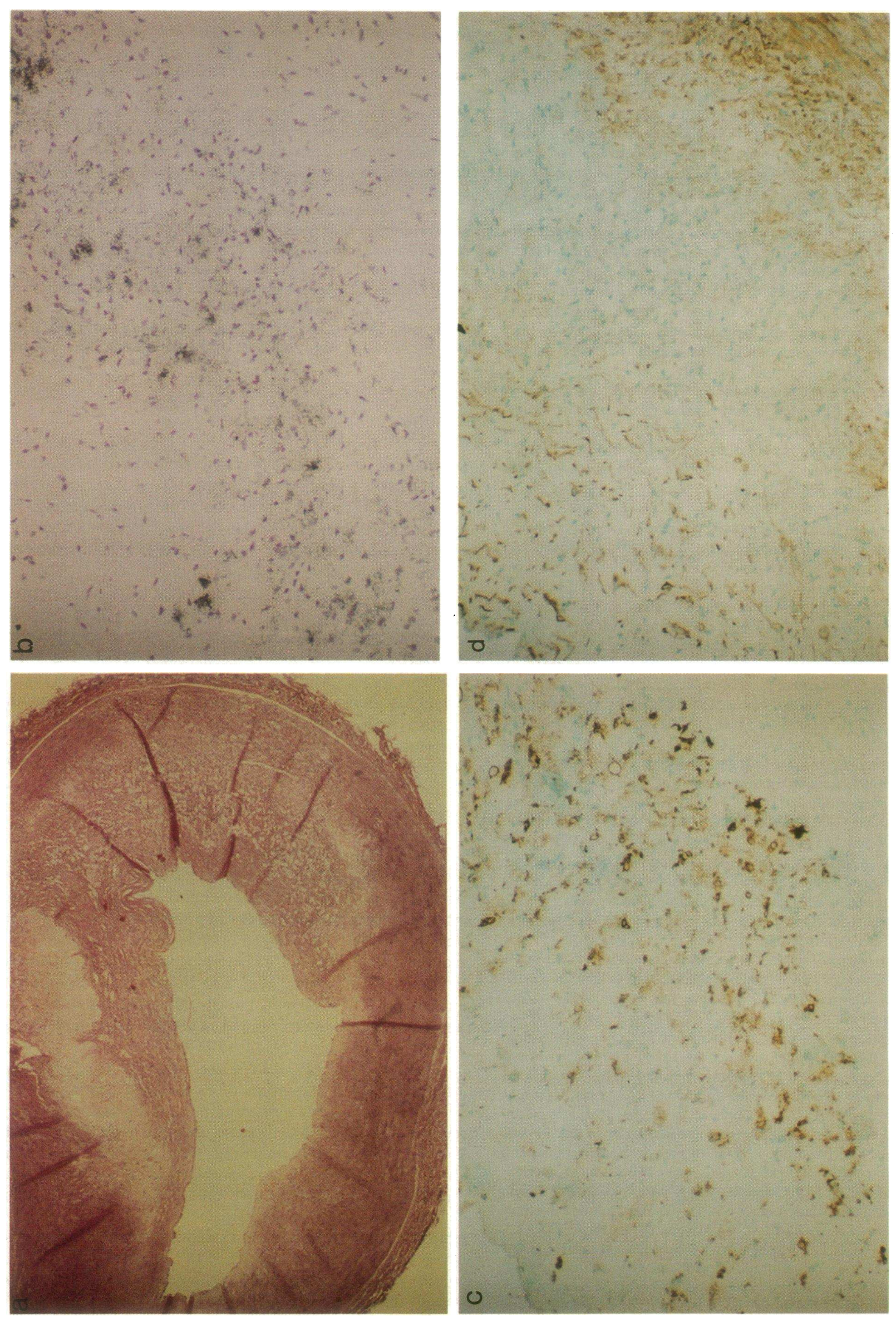

:

要

步

온

. 

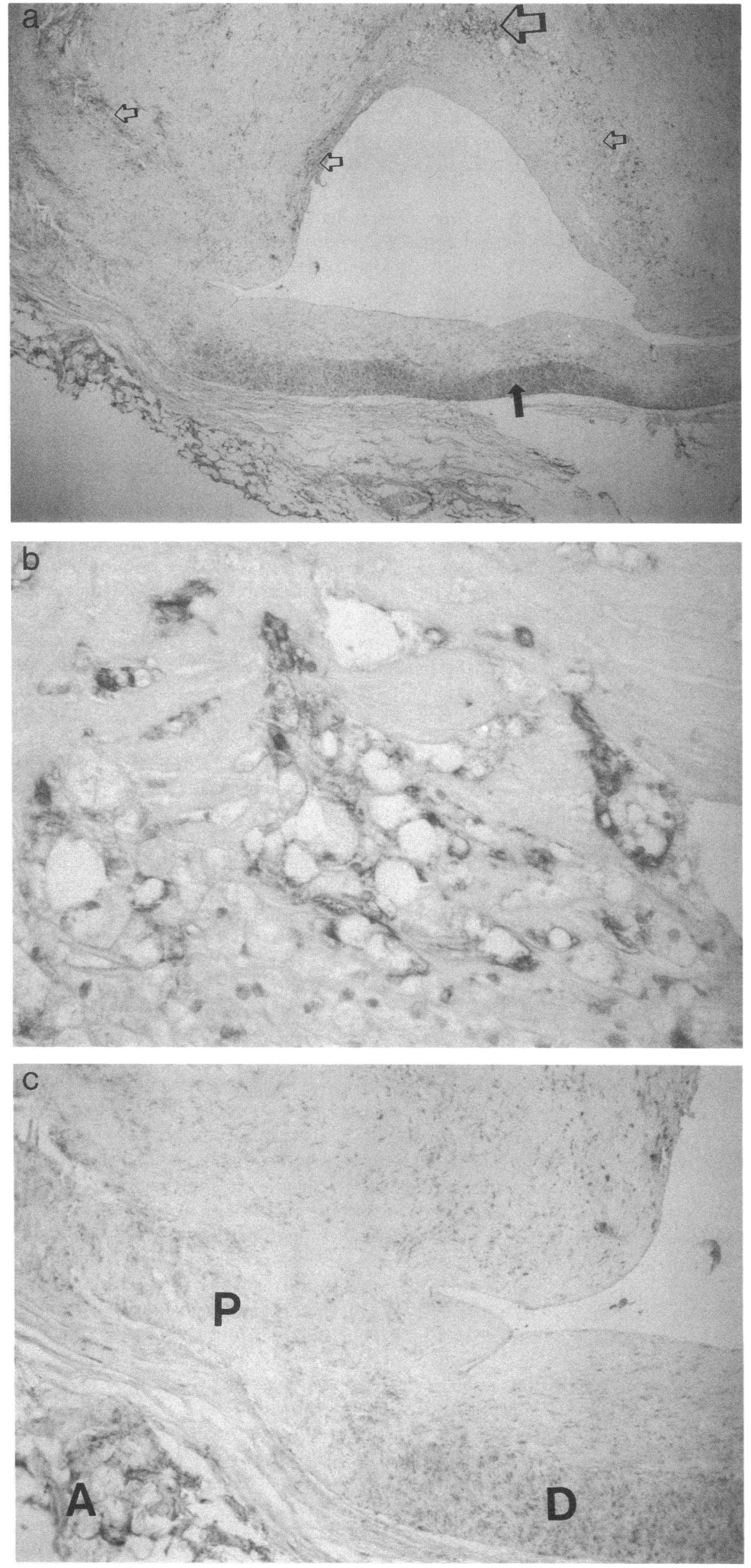

Figure 2. LPL immunocytochemistry. Immunoperoxidase staining of an arterial section with antibody LPL 5780 shows specific staining of adventitial fat (lower left) foam cells (open arrows) and medial smooth muscle cells (closed arrow) (a). A higher magnification view of a foam cell-rich region $(b)$ confirms specific staining of foam cells. LPL immunoreactivity $(c)$ is less intense in medial smooth muscle cells underlying plaque $(P)$ than in medial smooth muscle cells underlying an area of diffuse intimal thickening $(D)$ (original magnification: $(a), 40 ;(b), 400 ;(c)$, 100). 
Table I. Distribution of Cell Types and LPL MRNA in 48 Quadrants of Human Arterial Intima

\begin{tabular}{llcc}
\hline & & \multicolumn{2}{c}{ LPL mRNA } \\
\cline { 3 - 4 } & & Present & Absent \\
\hline \multirow{3}{*}{ Foam cells } & & $n=11$ & $n=37$ \\
Macrophages & Present $(n=10)$ & 10 & 0 \\
Smooth muscle cells & Absent $(n=38)$ & 1 & 37 \\
& Present $(n=29)$ & 11 & 18 \\
& Absent $(n=19)$ & 0 & 19 \\
& Present $(n=46)$ & 9 & 37 \\
& Absent $(n=2)$ & 2 & 0
\end{tabular}

containing quadrants contained LPL mRNA, while only one foam cell-negative quadrant had any detectable LPL mRNA. All LPL mRNA-positive quadrants contained some macrophages. However, a significant number $(40 \%)$ of macrophagecontaining quadrants had no detectable LPL mRNA. Again, these HAM-56-positive, LPL mRNA-negative quadrants contained nonfoamy macrophage cells as opposed to the foam cells described previously. Finally, the weakest association was that found for smooth muscle cells, in that 2 LPL mRNA-positive quadrants (22\%) had no smooth muscle cells, while 37 of smooth muscle cell-containing quadrants $(77 \%)$ had no detectable LPL mRNA. These results are consistent with results of comparison of adjacent sections (e.g., as shown in Fig. 1), which indicate that foam cells are the primary cellular source of LPL mRNA in coronary arterial plaques and that these foam cells are primarily of macrophage origin. However, neither this type of analysis nor analysis of adjacent sections labelled with each of the cell-specific antibodies or LPL riboprobe can definitively prove which cells of the plaque are the primary source of LPL mRNA. Therefore, combined immunocytochemistry with each of the cell-specific antibodies and in situ hybridization with the LPL riboprobe was performed on a limited number of arterial sections.

Combined immunocytochemistry and in situ hybridization. Fig. 3 shows a high power photomicrograph of a lesion stained with the macrophage-specific marker, HAM-56, and hybridized with the LPL riboprobe. The black silver grains, which indicate the presence of LPL mRNA, are associated with cells that can be identified as foam cells as evidenced by their morphology, and as of macrophage origin by their staining with the macrophage-specific antibody. Fig. 4 shows a high power photomicrograph of the fibrous cap of an adjacent section of the same lesion as shown in Fig. 3, but which has now been stained with the smooth muscle cell-specific antibody, HHF-35, and hybridized with the LPL riboprobe. Smooth muscle cells (brown reaction product) are not associated with the black silver grains that represent LPL mRNA. These findings contrast with the results of Jonasson et al. (11), who found that LPL protein, as identified by a polyclonal antibody, was found primarily in association with smooth muscle cells that did not express the major histocompatibility complex antigen HLADR, but only with a small minority of macrophages, and not with any foam cells.

\section{Discussion}

The findings of the present study strongly suggest that macrophages and, in particular, macrophage-derived foam cells rather than smooth muscle cells, are the primary cellular source of LPL, as detected by in situ hybridization, in human coronary plaques. In vitro and in vivo experiments have diverged in their conclusions about which of the cells of the plaque produce LPL. For example, several groups have been able to demonstrate the production of large quantities of LPL by cultured murine peritoneal (4), human blood monocytederived $(5,6)$, and rabbit alveolar (6) macrophages. Only one group has been able to demonstrate the production of relatively small quantities of LPL by pig aortic smooth muscle cells (7). In contrast, available data from a limited number of in vivo experiments have suggested that LPL protein is mostly associated with vascular smooth muscle cells, rather than macrophages. Camps et al. (10) have demonstrated that both LPL mRNA, as detected by in situ hybridization, and LPL protein as detected immunocytochemically, are associated with normal medial smooth muscle cells in guinea pig aorta. Neither atherosclerotic guinea pig aortas nor macrophages were examined in that study. Jonasson et al. (11) have detected LPL protein in association with HLA-DR-negative smooth muscle cells, but not to any significant degree with HLA-DR-positive smooth muscle cells, macrophages, or foam cells in human carotid plaques. Thus LPL has been most readily identified with macrophages in cell culture, but with smooth muscle cells in arterial tissue.

While the present study confirms that LPL protein is associated with some intimal smooth muscle cells, it is present at a much lower level than that found in macrophage-derived foam cells. Further, LPL staining of media underlying areas of welldeveloped plaque is less than that found in media underlying either normal intima or intima with diffuse thickening. One explanation for the difference between the findings of the present study and that of Jonasson et al. is that there may be a difference between the cellular source of LPL mRNA in human carotid plaques used in their study and human coronary arteries used in the present study. This explanation seems unlikely, however, as it would imply the presence of fundamentally different stimuli for, or mediators of, atherogenesis in the human carotid and coronary circulations. Another possibility is that the LPL associated with intimal smooth muscle cells in both the study of Jonasson et al. and in the present study, was synthesized and secreted by macrophages. It is well recognized that LPL may associate with cells other than those in which it was produced, the best example being endothelial cells (10). The findings in the present study are consistent with the observation that macrophages in culture produces large amounts of LPL $(4,5,6)$. A third possibility is that smooth muscle cells accumulate LPL mRNA in amounts that are beyond the level of detection by the in situ hybridization method used. Alternatively, but much less likely given the lability of the LPL protein, LPL mRNA could have been synthesized by smooth muscle cells at an earlier stage of atherogenesis. Regardless, the markedly low levels of LPL protein in intimal and medial smooth muscle cells underlying atherosclerotic plaque suggest that factors, such as cytokines, associated with the atherosclerotic process result in suppression of LPL associated with smooth muscle cells. The reason why Jonasson et al. were unable to localize LPL to macrophages by immunocytochemical methods (11) is not clear, particularly since LPL mRNA was exclusively localized to macrophages in the present study.

The localization of LPL mRNA to the most lipid-laden cells of human coronary plaques, i.e., foam cells, raises the question of whether these cells express LPL as a result of their 


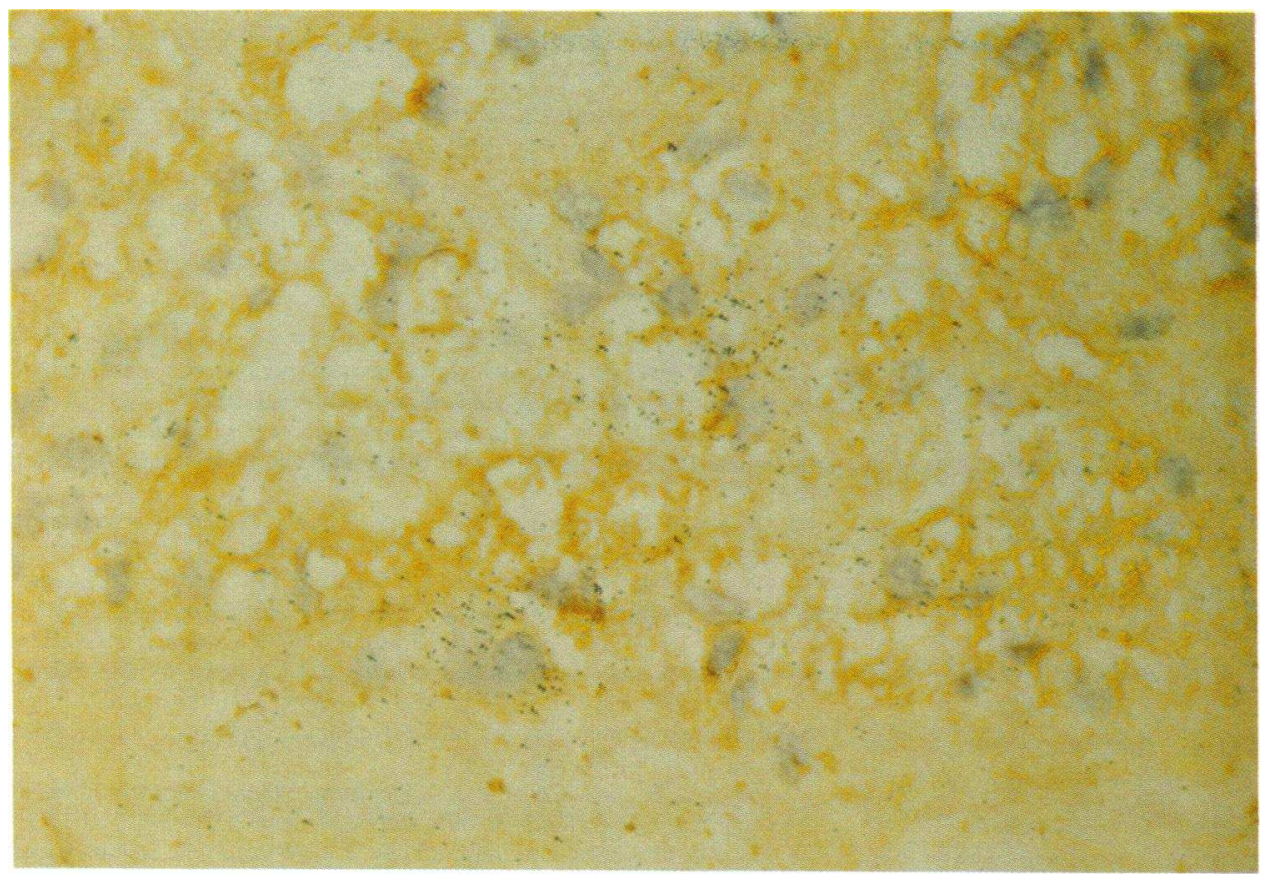

Figure 3. Combined macrophage-specific immunocytochemistry and LPL in situ hybridization. A foam cell-rich region is photographed both with normal illumination to demonstrate the co-localization of macrophage-derived foam cells (brown reaction product) and of the silver grains from the antisense LPL riboprobe. The production of LPL mRNA by macrophage-derived foam cells is confirmed (original magnification, 400).

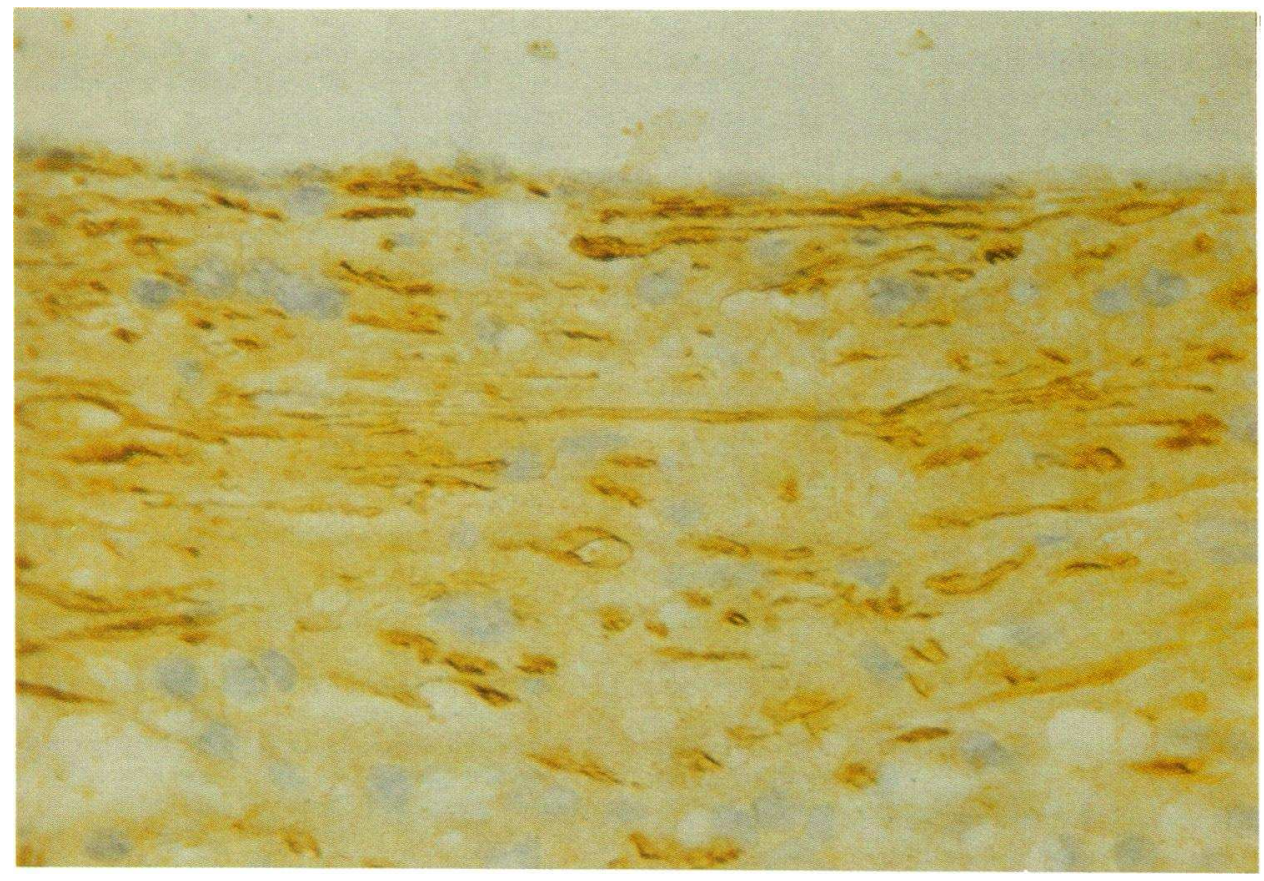

Figure 4. Combined smooth muscle cell-specific immunocytochemistry and LPL in situ hybridization. A fibrous cap is photographed to demonstrate the location of smooth muscle cells (brown reaction product). There is no specific hybridization of the LPL riboprobe with smooth muscle cells (original magnification, 400).

morphologic transformation into foam cells, or that expression of high levels of LPL by some macrophages enhances their ability to become foam cells as a result of enhanced uptake of modified lipoproteins. The finding in the present study that some non-foam cell macrophages produce LPL mRNA supports the latter hypothesis. It is noteworthy that only advanced atherosclerotic plaques were examined in the present study, so that LPL expression by earlier lesions, such as fatty streaks, could not be determined.

The finding that LPL mRNA is not detectable in a percentage of intimal macrophages also has at least two potential explanations. First, it may be that the method used does not detect 
LPL mRNA expressed by cells at a relatively low level. This could also explain our inability to detect LPL mRNA in medial smooth muscle cells. Because a certain amount of nonspecific background is invariably present when radioactively labelled riboprobes are used, low level mRNA expression may not provide sufficient signal above background to allow detection. Examination of sections stained with the antisense riboprobe used in our study show that very little background is present. Therefore, if LPL mRNA expression was present but not detected in some macrophages or in smooth muscle cells, the levels of mRNA present would be much lower than that seen in foam cells. However, this would not invalidate the conclusion that macrophage-derived foam cells are the primary cellular source of LPL in human coronary plaques, consistent with observations in vitro. Low level expression or lack of expression of LPL by some intimal macrophages suggests that these macrophages may be under the influence of cytokines which inhibit LPL expression, such as interferon-gamma $(17,18)$ produced by $T$ lymphocytes. In addition, Hansson et al., have shown that $\mathrm{T}$ lymphocytes are present in human atherosclerotic lesions (19) and in lesions from cholesterol-fed rabbits (20), suggesting that T lymphocyte-derived cytokines such as interferon-gamma may be involved in atherogenesis. If intimal $\mathrm{T}$ lymphocytes have the ability to retard atherogenesis, one way in which they might do this is by suppressing LPL expression by neighboring macrophages through secretion of interferon-gamma.

Whether LPL might play a role in the pathogenesis of atherosclerosis is unknown, but Zilversmit has postulated that LPL may promote atherosclerosis, by modifying triglyceriderich lipoproteins at the endothelial surface to atherogenic remnants (2). In vitro experiments which demonstrate that LPL may modify VLDL (8) and LDL (9) to more atherogenic forms support the hypothesis that LPL expressed in atherosclerotic plaques may be proatherogenic. The present study demonstrates that LPL is expressed in the intima of plaques, being produced primarily by the most lipid-laden cells of the plaque, i.e., macrophage-derived foam cells. Further, LPL mRNA may be expressed by some intimal non-foam cell macrophages, raising the possibility that LPL plays a role in the lipid accumulation that is a hallmark of their morphologic transformation into foam cells, although its presence in macrophages does not necessarily imply a role for LPL in this process. Some subjects who are heterozygous for LPL deficiency might be at increased risk of atherosclerosis by virtue of the atherogenic profiles seen in this situation (21). However, sufficient LPL is likely to be present in the milieux of the artery wall for local modification of lipoproteins by macrophage-derived LPL. ${ }^{2}$

\section{Acknowledgments}

The authors wish to thank Elaine Yamanaka and Reiling Peng for technical assistance and Julie Hildebrand for preparing the manuscript and to gratefully acknowledge the contributions of Drs. Margaret Allen

2. During review of this manuscript, a paper demonstrating similar findings appeared in press (22). and Dan Fishbein of the Cardiac Transplant Service at the University of Washington.

This work was supported by National Institutes of Health grants DK02456 (Dr. Chait), HL-30086 (Drs. Chait and Deeb), and HL42119 and HL-42770 (Dr. Gordon). Dr. O'Brien was a Research Fellow of the American Heart Association, Washington Affiliate.

\section{References}

1. Eckel, R. H. 1989. Lipoprotein lipase: a multifunctional enzyme relevant to common metabolic diseases. $N$. Engl. J. Med. 320:1060-1068.

2. Zilversmit, D. B. 1973. A proposal linking atherogenesis to the interaction of endothelial lipoportein lipase with triglyceride-rich lipoproteins. Circ. Res. 33:633-638.

3. DiCorletto, P. E., and D. B. Zilversmit. 1975. Lipoprotein lipase activity in bovine aorta. Proc. Soc. Exp. Biol. Med. 148:1101-1105.

4. Khoo, J. C., E. M. Mahoney, and J. L. Witztum. 1981. Secretion of lipoprotein lipase by macrophages in culture. J. Biol. Chem. 256:7105-7108.

5. Chait, A., P.-H. Iverius, and J. D. Brunzell. 1982. Lipoprotein lipase secretion by human monocyte-derived macrophages. J. Clin. Invest. 69:490-493.

6. Mahoney, E. M., J. C. Khoo, and D. Steinberg. 1982. Lipoprotein lipase secretion by human monocytes and rabbit alveolar macrophages in culture. Proc. Natl. Acad. Sci. USA 79:1639-1642.

7. Vance, J. E., J. C. Khoo, and D. Steinberg. 1982. Lipoprotein lipase in cultured pig aortic smooth muscle cells. Arteriosclerosis. 2:390-395.

8. Lindqvist, P., A.-M. Ostlund-Lindqvist, J. L. Witztum, D. Steinberg, and J. A. Little. 1983. The role of lipoprotein lipase in the metabolism of triglyceriderich lipoproteins by macrophages. J. Biol. Chem. 258:9086-9092.

9. Aviram, M., E. L. Bierman, and A. Chait. 1988. Modification of low density lipoprotein by lipoprotein lipase or hepatic lipase induces enhanced uptake and cholesterol accumulation in cells. J. Biol. Chem. 263:15416-15422.

10. Camps, L., M. Reina, M. Llobera, S. Vilaro, and T. Olivecrona. 1990. Lipoprotein lipase: cellular origin and functional distribution. Am. J. Physiol. 258 (Cell Physiol. 27):C673-C678.

11. Jonasson, L., G. Bondjers, and G. K. Hansson. 1987. Lipoprotein lipase in atherosclerosis: its presence in smooth muscle cells and absence from macrophages. J. Lipid Res. 28:437-445.

12. Tsukada, T., D. Tippens, D. Gordon, R. Ross, and A. M. Gown. 1987. HHF-35, a muscle-actin-specific monoclonal antibody. I. Immunocytochemical and biochemical characterization. Am. J. Pathol. 126:51-60.

13. Gown, A. M., T. Tsukada, and R. Ross. 1986. Human atherosclerosis. II. Immunocytochemical analysis of the cellular composition of human atherosclerotic lesions. Am. J. Pathol. 125:191-207.

14. Auwerx, J. H., S. Deeb, J. D. Brunzell, R. Peng, and A. Chait. 1988. Transcriptional activation of the lipoprotein lipase and apolipoprotein $\mathrm{E}$ genes accompanies differentiation in some human macrophage-like cell lines. Biochemistry. 27:2651-2655.

15. Domin, W. S., A. Chait, and S. S. Deeb. 1991. Transcriptional activation of the lipoprotein lipase gene in macrophages by dexamethasone. Biochemistry. 30:2570-2574.

16. Deeb, S. S., and R. Peng. 1989. Structure and function of the human lipoprotein lipase gene. Biochemistry. 28:4131-4135.

17. Jonasson, L., G. K. Hansson, G. Bondjers, L. Noe, and J. Etienne. 1990. Interferon-gamma inhibits lipoprotein lipase in human monocyte-derived macrophages. Biochim. Biophys. Acta. 1053:43-48.

18. Querfeld, U., J. M. Ong, J. Prehn, B. Carty, B. Saffari, S. C. Jordan, and P. C. Kern. 1990. Effects of cytokines on the production of lipoprotein lipase in cultured human macrophages. J. Lipid Res. 31:1379-1386.

19. Hansson, G. K., J. Holm, L. Jonasson. 1989. Detection of activated T lymphocytes in the human atherosclerotic plaque. Am. J. Pathol. 135:169-175.

20. Hansson, G. K., P. S. Seifert, G. Olsson, and G. Bondjers. 1991. Immunohistochemical detection of macrophages and $\mathrm{T}$ lymphocytes in atherosclerotic lesions of cholesterol-fed rabbits. Arterioscler. Thromb. 11:745-750.

21. Babirak, S. P., P.-H. Iverius, W. Y. Fujimoto, and J. D. Brunzell. 1989. Detection and characterization of the heterozygous state for lipoprotein lipase deficiency. Arteriosclerosis. 9:326-334.

22. Yla-Hertualla, S., B. A. Lipton, M. E. Rosenfeld, I. J. Goldberg, D. Steinberg, and J. C. Witztum. 1991. Macrophages and smooth muscle cells express lipoprotein lipase in human and rabbit atherosclerotic lesions. Proc. Natl. Acad. Sci. USA. 88:10143-10147. 